OPEN Electronic excitation induced

SUBJECT AREAS:

CERAMICS

PHASE TRANSITIONS AND CRITICAL PHENOMENA

Received

6 August 2014

Accepted

14 January 2015

Published

9 February 2015

Correspondence and requests for materials should be addressed to H.Y.X. (hyxiao@uestc. edu.cn) \section{amorphization in titanate pyrochlores: an ab initio molecular dynamics study}

\author{
H. Y. Xiao' , W. J. Weber ${ }^{2,3}$, Y. Zhang ${ }^{3}$, X. T. Zu ${ }^{1,4} \&$ S. Li ${ }^{5}$
}

\begin{abstract}
${ }^{1}$ School of Physical Electronics, University of Electronic Science and Technology of China, Chengdu 610054, China, ${ }^{2}$ Department of Materials Science \& Engineering, University of Tennessee, Knoxville, TN 37996, USA, ${ }^{3}$ Materials Science \& Technology Division, Oak Ridge National Laboratory, Oak Ridge, TN 37831, USA, ${ }^{4}$ Institute of Fundamental and Frontier Sciences, University of Electronic Science and Technology of China, Chengdu 610054, China, ${ }^{5}$ School of Material Science and Engineering, University of New South Wales, Sydney, 2052, Australia.
\end{abstract}

The response of titanate pyrochlores $\left(\mathrm{A}_{2} \mathrm{Ti}_{2} \mathrm{O}_{7}, \mathrm{~A}=\mathrm{Y}, \mathrm{Gd}\right.$ and $\left.\mathrm{Sm}\right)$ to electronic excitation is investigated utilizing an $a b$ initio molecular dynamics method. All the titanate pyrochlores are found to undergo a crystalline-to-amorphous structural transition under a low concentration of electronic excitations. The transition temperature at which structural amorphization starts to occur depends on the concentration of electronic excitations. During the structural transition, $\mathrm{O}_{2}$-like molecules are formed, and this anion disorder further drives cation disorder that leads to an amorphous state. This study provides new insights into the mechanisms of amorphization in titanate pyrochlores under laser, electron and ion irradiations.

T he response of complex ceramics to extreme environments is of great interest for a broad range of applications. Ceramics for nuclear applications are exposed to high radiation environments that can lead to microstructure evolution, phase transitions, and degradation of physical and chemical properties. Ions, electrons and intense laser pulses can be used for precision micromachining, forming nanostructures, processing thin films, and inducing phase transitions. Pyrochlore-structured oxides, with the general formula $\mathrm{A}_{2} \mathrm{~B}_{2} \mathrm{O}_{7}(\mathrm{~A}=$ $\mathrm{Y}$ or another rare earth element; $\mathrm{B}=\mathrm{Ti}, \mathrm{Zr}$, Sn or $\mathrm{Hf})^{1,2}$, represent a broad class of complex ceramics that exhibit an enormous range of physical, chemical and electric properties, including high ionic conductivity, superconductivity, luminescence, and ferromagnetism ${ }^{3}$. This leads to their significant potential use in a wide range of technical applications, such as hosts for oxidation catalysts, solid electrolytes in high temperature fuel cells, and ceramic thermal barrier coatings ${ }^{4-6}$. Modifying properties and creating new functionalities in pyrochlore thin films, single crystals and bulk materials often involves electron, ion or pulsed laser irradiation. Chemically durable pyrochlores are also candidate host matrices for the immobilization of plutonium and minor actinides that are generated through reprocessing of spent fuel from nuclear reactors ${ }^{3,7-9}$.

During the past decade, there have been many studies of ion-irradiation effects in pyrochlores ${ }^{10-16}$, and excimer laser irradiation has been employed to process pyrochlore thin films ${ }^{17}$, induce phase transitions ${ }^{18}$, and embed pyrochlore nanostructures ${ }^{19}$. Some pyrochlores undergo a structural phase transition from ordered pyrochlore to an amorphous structure due to self-radiation from actinide decay ${ }^{20}$ or external ion irradiation ${ }^{21}$. For example, amorphization was observed in the pyrochlore $\mathrm{Gd}_{2} \mathrm{Ti}_{2} \mathrm{O}_{7}$ due to self-radiation damage from $\alpha$-decay of incorporated ${ }^{244} \mathrm{Cm}$ at room temperature ${ }^{20,22}$. Lian et al. have investigated the irradiation response of $\mathrm{A}_{2} \mathrm{Ti}_{2} \mathrm{O}_{7}(\mathrm{~A}=\mathrm{Sm}$ to $\mathrm{Lu}$, and $\mathrm{Y}$ ) pyrochlores by $1-\mathrm{MeV} \mathrm{Kr}$ ions at temperatures from 293 to $1073 \mathrm{~K}$, and found that most of the titanate pyrochlores are readily amorphized ${ }^{23}$. Several possible mechanisms, such as direct-impact (in-cascade) amorphization within an individual collision cascade, the local accumulation of high defect concentrations due to the overlap of collision cascades, or a combination of these processes have been proposed to explain the origin of irradiation-induced amorphization ${ }^{24,25}$. These mechanisms are mainly based on atomic collision processes caused by energy transfer from energetic charged particles to atomic nuclei. Besides this effect, electronic excitation or ionization arising from the electronic energy loss of energetic ions may also weaken local atomic bonds and cause the collapse of the crystalline phase and structural amorphization at temperatures below the melting point ${ }^{26,27}$. In recent years, several swift heavy ion irradiation investigations have been carried out on pyrochlores to study the effects of intense electronic excitation ${ }^{28-34}$. The large local electronic excitation that occurs along an individual ion path leads to a thermal spike that creates an amorphous track in titanate pyrochlores ${ }^{30}$, and full amorphization 


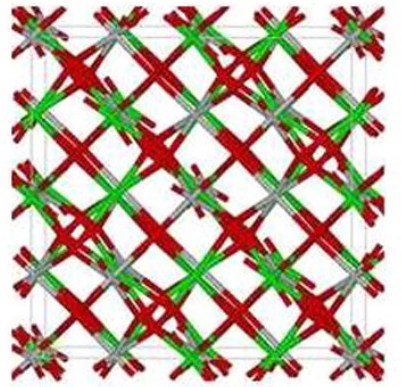

(a)

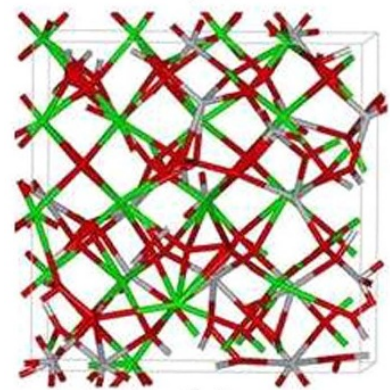

(c)

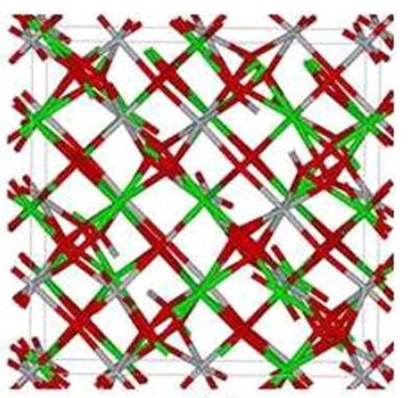

(b)

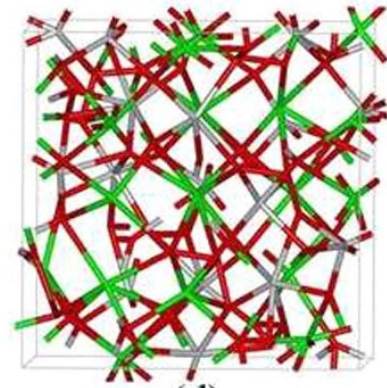

(d)
Figure $1 \mid$ Geometrical configuration of $\mathrm{Gd}_{2} \mathrm{Ti}_{2} \mathrm{O}_{7}$ with excitation concentration of (a) $0.0 \%$; (b) $0.99 \%$; (c) $1.64 \%$ and (d) $2.30 \%$ at $300 \mathrm{~K}$. The green, grey and red sticks represent $\mathrm{Gd}, \mathrm{Ti}$ and $\mathrm{O}$, respectively.

results from the overlapping of these tracks ${ }^{32}$. Moll et al. compared the structural transitions in $\mathrm{Gd}_{2} \mathrm{Ti}_{2} \mathrm{O}_{7}$ single crystals irradiated with high- and low-energy heavy ions (870-MeV Xe and 4-MeV Au), and suggested that at high energy the structural amorphization is dominated by high electronic excitation, while at low energy the amorphization is driven by ballistic nuclear energy deposition from the ions $^{35}$. More recently, Thomé et al. observed that ionization from $36-\mathrm{MeV} \mathrm{W}$ ions contributes to amorphization in $\mathrm{Gd}_{2} \mathrm{Ti}_{2} \mathrm{O}_{7}{ }^{36}$, although the mechanism for the ionization-induced amorphization was not identified.

Experimentally, electron beam irradiation using transmission electron microscopy is a direct technique to simulate the effects of electronic excitation and ionization from $\beta$-particles and $\gamma$-rays in reasonable laboratory time periods $s^{37,38}$. This technique has been employed to study the electronic effects on preamorphized $\mathrm{SrTiO}_{3}$ and $\mathrm{Sr}_{2} \mathrm{Nd}_{8}\left(\mathrm{SiO}_{4}\right)_{6} \mathrm{O}_{2}$, and electron-beam-induced recrystallization

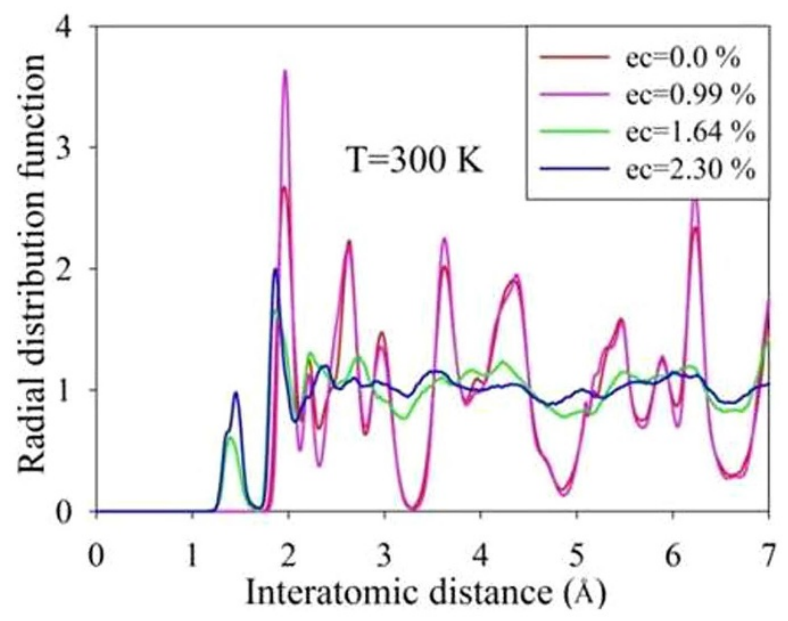

Figure 2 Radial distribution functions as a function of excitation concentration for $\mathrm{Gd}_{2} \mathrm{Ti}_{2} \mathrm{O}_{7}$ at $300 \mathrm{~K}$.

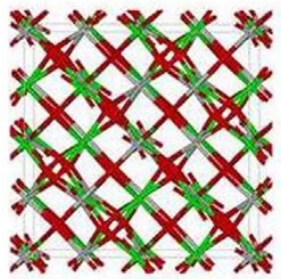

$\mathrm{t}=0 \mathrm{ps}$

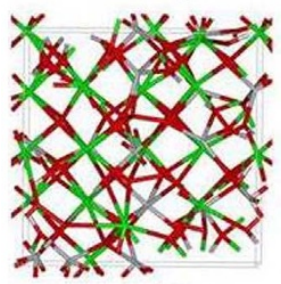

$\mathrm{t}=0.9 \mathrm{ps}$

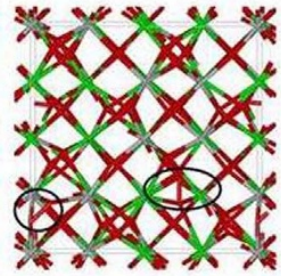

$\mathrm{t}=0.3 \mathrm{ps}$

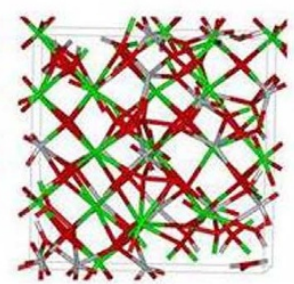

$\mathrm{t}=3 \mathrm{ps}$

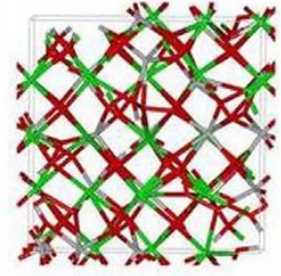

$\mathrm{t}=0.6 \mathrm{ps}$

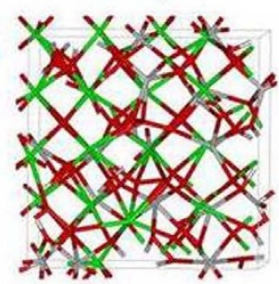

$\mathrm{t}=15 \mathrm{ps}$
Figure $3 \mid$ Structural evolution of $\mathrm{Gd}_{2} \mathrm{Ti}_{2} \mathrm{O}_{7}$ with $1.64 \%$ excitation at $300 \mathrm{~K} . \mathrm{O}_{2}$-like molecules are marked by the black circles.

was observed ${ }^{39-41}$, demonstrating that electronic excitation or ionization from electron irradiation can have substantial effects on the structure of materials. This raises the question of the role of electronic excitation at lower ion energies on the irradiation-induced crystalline-to-amorphous transition in pyrochlores, i.e., whether electronic excitation contributes to the amorphization or not. What will happen if only a small fraction of electrons in pyrochlores is excited? Theoretically, simulation of electronic excitation effects is a challenging task, since the dynamics of electron-hole recombination should be considered, and new computational techniques are needed to describe this effect ${ }^{41}$. In this study, an $a b$ initio molecular dynamics (AIMD) method ${ }^{42,43}$ is employed to explore how low electronic excitation influences microstructural evolution in titanate pyrochlores. It is shown that at room temperature even $\sim 2 \%$ electronic excitation can induce structural amorphization, with the formation of $\mathrm{O}_{2}$-like molecules during the amorphization process. This mechanism is found to be different from that of intense electronic excitation induced by swift heavy ions irradiation, where local melting from a thermal spike leads to a quenched melt structure ${ }^{30}$. Our calculations suggest that electronic excitation may contribute to structural amorphization of pyrochlores under low or medium energy electron and ion irradiation. While intense electron and pulsed laser irradiation studies on $\mathrm{Gd}_{2} \mathrm{Ti}_{2} \mathrm{O}_{7}$ and other rare-earth titanate pyrochlores have not yet reported, the results of the present study provide some guidance on what might be expected.

\section{Computational Details}

All the calculations were carried out within the density functional theory (DFT) framework using the projector augmented wave method, as implemented in the Vienna Ab Initio Simulation Package (VASP) ${ }^{44}$. Projector augmented-wave pseudopotentials ${ }^{45}$ were used to describe the interaction between ions and electrons, and the exchange-correlation effects were treated using the generalized gradient approximation (GGA) in the Perdew-Wang parameterization. The valence electronic configurations are $6 s^{2} 5 p^{6} 5 d^{1}$ for Gd, $4 s^{2} 4 p^{6} 5 s^{1} 4 d^{2}$ for Y, $5 s^{2} 6 s^{2} 5 p^{6} 5 d^{1}$ for Sm, $4 s^{1} 3 d^{3}$ for Ti and $2 s^{2} 2 p^{4}$ for $\mathrm{O}$. Computations were based on a supercell consisting of 88 atoms, with a $1 \times 1 \times 1$ Monkhorst-Pack ${ }^{46} \mathrm{k}$-point sampling in the Brillouin zone and a cutoff energy of $400 \mathrm{eV}$ for the basis set. The calculated lattice parameters are $\mathrm{a}_{0}=10.11 \AA, x_{\mathrm{O} 48 \mathrm{f}}=0.3301$ for $\mathrm{Y}_{2} \mathrm{Ti}_{2} \mathrm{O}_{7}, \mathrm{a}_{0}=10.22 \AA, x_{\mathrm{O} 48 \mathrm{f}}=0.3292$ for $\mathrm{Gd}_{2} \mathrm{Ti}_{2} \mathrm{O}_{7}$, and $\mathrm{a}_{0}=$ $10.31 \AA, x_{\mathrm{O} 48 \mathrm{f}}=0.3269$ for $\mathrm{Sm}_{2} \mathrm{Ti}_{2} \mathrm{O}_{7}$, which agree well with the experimental results and other calculations ${ }^{5,23}$. The crystal was first equilibrated for 2 ps at $100 \mathrm{~K}$. To study the response of titanate 


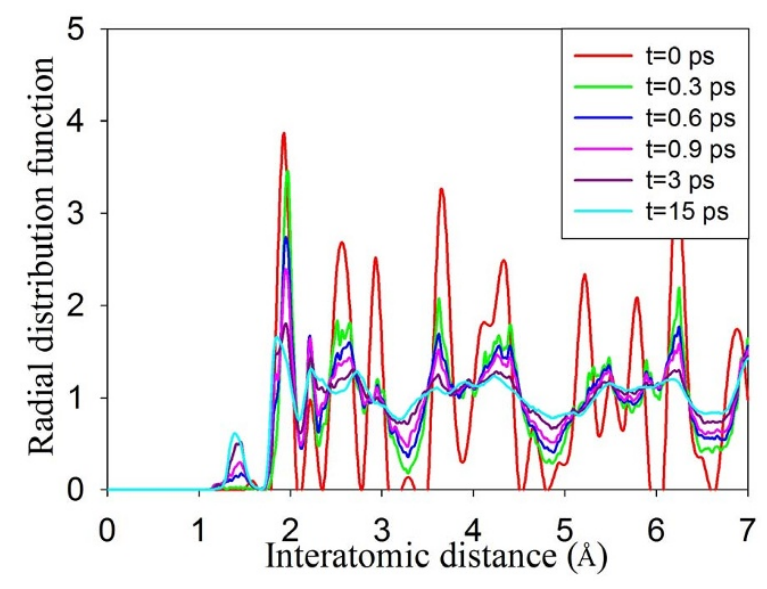

Figure $4 \mid$ Radial distribution functions as a function of time for $\mathrm{Gd}_{2} \mathrm{Ti}_{2} \mathrm{O}_{7}$ at $300 \mathrm{~K}$.

pyrochlores to electronic excitation, we simplified the simulation by removing several electrons from high-lying valence band states and a jellium background was used to compensate for the loss of charge due to electron removal. Selection of the electrons that should be removed was weighted according to the orbital energies. This method has been suggested and validated by $\mathrm{Li}$ et al. in studies of the role of electronic excitation in the amorphization of Ge-Sb-Te alloys $^{47}$. The excitation concentration, which is defined as the ratio of the number of excited valence electrons to the number of total electrons, varies from 0 to $2.3 \%$. Since the supercell contains 1824 electrons for $\mathrm{Gd}_{2} \mathrm{Ti}_{2} \mathrm{O}_{7}, 1424$ electrons for $\mathrm{Y}_{2} \mathrm{Ti}_{2} \mathrm{O}_{7}$ and 1792 electrons for $\mathrm{Sm}_{2} \mathrm{Ti}_{2} \mathrm{O}_{7}$, the maximum excitation concentration of $2.3 \%$ correspond to 42,33 and 41 excited electrons, respectively. Under laser beam irradiation, the laser fluence at $400 \mathrm{~nm}$ for $1 \%$ excitation in $\mathrm{Gd}_{2} \mathrm{Ti}_{2} \mathrm{O}_{7}$ is estimated to be about $9.5 \times 10^{2}-5.4 \times 10^{3} \mathrm{~mJ} / \mathrm{cm}^{2}$ (see supplementary material). Ab initio $\mathrm{MD}$ calculations were then performed to completely relax the whole system until it reached an equilibrium state at temperatures of interest. Subsequently, the removed electrons were placed back to mimic the recombination of electrons and holes. The AIMD simulation was conducted with a time step of $3 \mathrm{fs}$ and a isothermal-isochoric ensemble, in which the Nosé-Hoover thermostat was employed to control the temperature. The simulation times are 12 ps and 3 ps for electronic excitation and electron-hole recombination, respectively.

\section{Results and Discussion}

AIMD simulations were first carried out on $\mathrm{Gd}_{2} \mathrm{Ti}_{2} \mathrm{O}_{7}$ at $300 \mathrm{~K}$ with the concentration of excited electrons being $0.0 \%, 0.99 \%, 1.64 \%$ and

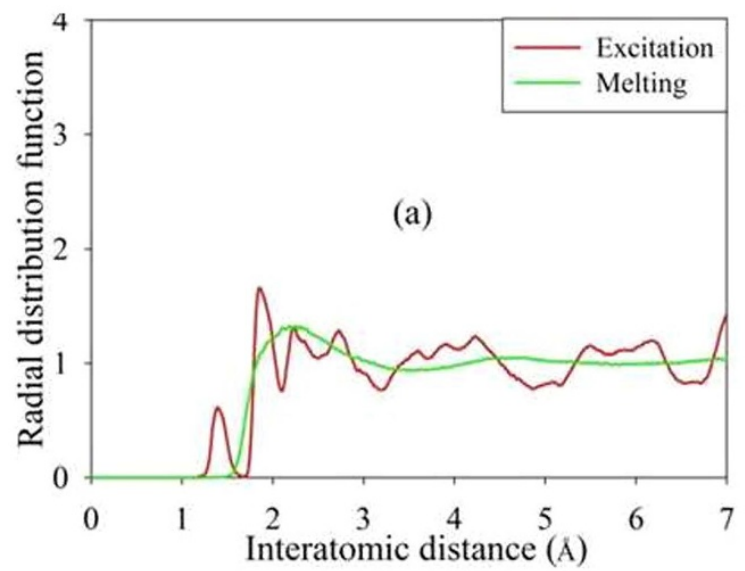

$2.30 \%$. The results in Fig. 1 show the final geometrical configurations of $\mathrm{Gd}_{2} \mathrm{Ti}_{2} \mathrm{O}_{7}$ for different excitation concentrations. The pyrochlore structure remains ordered when no electrons are excited, and the ordered structure changes very slightly for $0.99 \%$ excitation. However, significant structural changes occur for $1.64 \%$ and $2.30 \%$ excitation. Atomic coordination analysis shows that the Gd and $\mathrm{Ti}$ atoms are eight- and six-coordinated with oxygen atoms in the ideal pyrochlore structure; whereas for $1.64 \%$ excitation, the average coordination numbers are lowered to 4.6 and 4.5 for $\mathrm{Gd}$ and $\mathrm{Ti}$, respectively. The radial distribution function (RDF), shown in Fig. 2, is a measure of the structural order as a function of excitation concentration for $\mathrm{Gd}_{2} \mathrm{Ti}_{2} \mathrm{O}_{7}$ at $300 \mathrm{~K}$. A material is amorphous when it retains short-range order but has lost long-range order. The results in Fig. 2 clearly show that the structures are ordered at shortrange distances and disordered at long-range distances for $1.64 \%$ and $2.30 \%$ excitation, suggesting that $1.64 \%$ and $2.30 \%$ electronic excitation can induce a crystalline-to-amorphous transition in $\mathrm{Gd}_{2} \mathrm{Ti}_{2} \mathrm{O}_{7}$ at $300 \mathrm{~K}$. Snapshots of structural evolution with $1.64 \%$ excitation are illustrated in Fig. 3 and the corresponding RDFs are presented in Fig. 4. It is shown that structural amorphization starts at $\mathrm{t}=0.3 \mathrm{ps}$, and the structure is completely amorphized at $\mathrm{t}=3 \mathrm{ps}$.

In order to explore if the structural amorphization is a solid-liquid transition, the melting point of $\mathrm{Gd}_{2} \mathrm{Ti}_{2} \mathrm{O}_{7}$ was calculated by annealing a high-temperature melt state at lower temperatures until the free energy starts to decrease and is accompanied by recrystallization ${ }^{47}$. The melting point was determined to be $\sim 1875 \mathrm{~K}$, which is $\sim 100 \mathrm{~K}$ lower than the experimental value of $\sim 1973 \mathrm{~K}^{48}$. AIMD simulations without electronic excitation were then performed at $2000 \mathrm{~K}$. Comparison of the RDF and mean square displacement (MSD) between the excited and melted $\mathrm{Gd}_{2} \mathrm{Ti}_{2} \mathrm{O}_{7}$ are shown in Figs. 5(a) and (b). It is noted that excitation-induced amorphization exhibits features significantly different from those of melt state. In the latter case, the structure is liquid and the MSD is $\sim 50$ times larger. These results indicate that electronic excitation-induced amorphization is a solid-solid transition rather than a solid-liquid transition.

Figure 6 shows that the system energy increases with increasing excitation concentration and becomes more and more close to that of the liquid amorphous state. Above an excitation concentration of $1.36 \%$, the system energy for $\mathrm{Gd}_{2} \mathrm{Ti}_{2} \mathrm{O}_{7}$ is even larger than that for the melt state. These results indicate that, at higher excitation concentration, the energy barrier for structural amorphization decreases and the crystalline-to-amorphous transition is much easier to occur.

Irradiation damage effects of titanate pyrochlores have been investigated experimentally over a broad range of ion irradiation energy. Under 1-MeV Kr ion irradiation, where the energy loss to ionization is much larger than the damage energy going into atomic displacements, it was observed that all the titanate pyrochlores are easily amorphized under irradiation ${ }^{23}$. Swift heavy ion irradiation, with

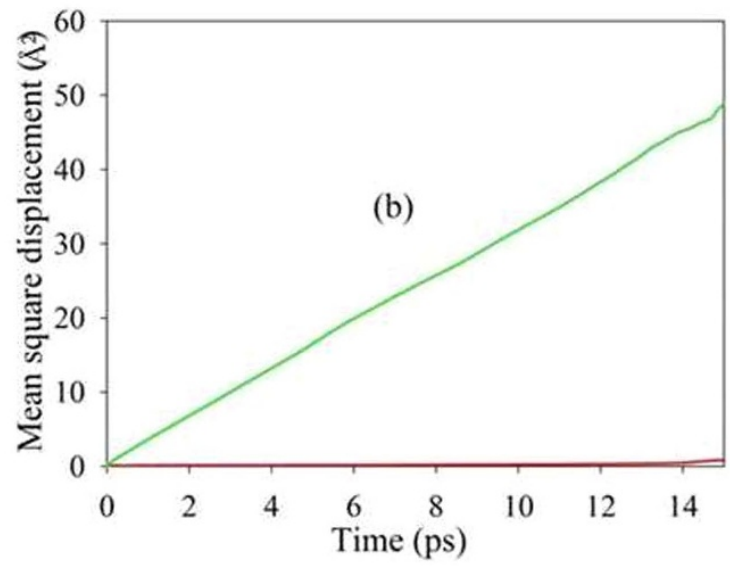

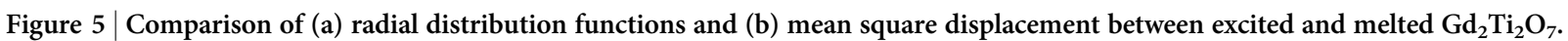




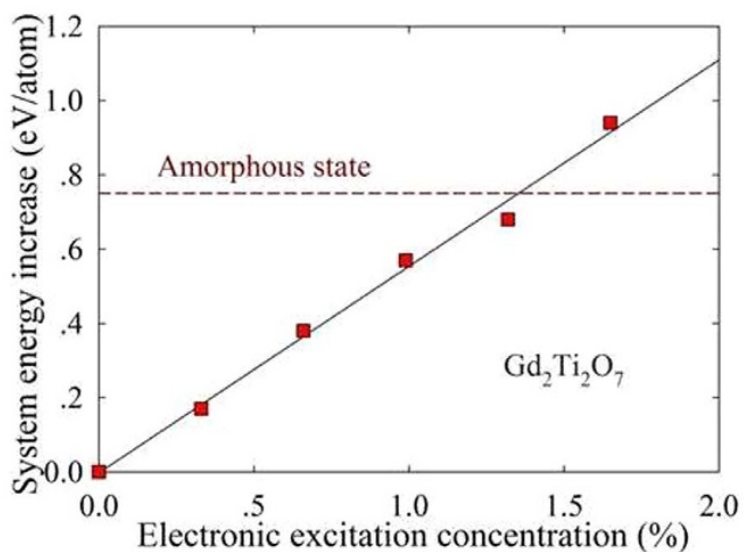

Figure 6 System energy increase in $\mathrm{Gd}_{2} \mathrm{Ti}_{2} \mathrm{O}_{7}$ as a function of electronic excitation concentration.

1.43-GeV Xe ions by Lang et al. ${ }^{29,30}$, with $100-\mathrm{MeV}$ ions by Patel et al. $^{28}$, with $780-\mathrm{MeV} \mathrm{Kr}$ ions, $870-\mathrm{MeV}$ Xe ions, $940-\mathrm{MeV} \mathrm{Pb}$ ions ${ }^{31}$ and $119-\mathrm{MeV} \mathrm{U}$ ions by Sattonnay et al. ${ }^{32}$, have been carried out on the $\mathrm{Gd}_{2}\left(\mathrm{Zr}_{\mathrm{x}} \mathrm{Ti}_{1-\mathrm{x}}\right)_{2} \mathrm{O}_{7}$ system, as well as a series of zirconate pyrochlores. These studies show that structural modification induced by high electronic excitation is chemical composition dependent. At intermediate ion energies, Thomé et al. observed amorphization in $\mathrm{Gd}_{2} \mathrm{Ti}_{2} \mathrm{O}_{7}$ due to ionization from $36-\mathrm{MeV} \mathrm{W}$ ions ${ }^{36}$.

To investigate if low electronic excitation induced amorphization is a universal phenomenon in other titanate pyrochlores, AIMD simulations are also carried out on $\mathrm{Y}_{2} \mathrm{Ti}_{2} \mathrm{O}_{7}$ and $\mathrm{Sm}_{2} \mathrm{Ti}_{2} \mathrm{O}_{7}$, in which $2.11 \%$ and $1.67 \%$ electrons are excited at $300 \mathrm{~K}$, respectively. The radial distribution functions of $\mathrm{Y}_{2} \mathrm{Ti}_{2} \mathrm{O}_{7}$ and $\mathrm{Sm}_{2} \mathrm{Ti}_{2} \mathrm{O}_{7}$ are compared with those of $\mathrm{Gd}_{2} \mathrm{Ti}_{2} \mathrm{O}_{7}$ with $1.64 \%$ excitation at $300 \mathrm{~K}$ in Fig. 7. Similar to $\mathrm{Gd}_{2} \mathrm{Ti}_{2} \mathrm{O}_{7}$, both $\mathrm{Y}_{2} \mathrm{Ti}_{2} \mathrm{O}_{7}$ and $\mathrm{Sm}_{2} \mathrm{Ti}_{2} \mathrm{O}_{7}$ undergo a crystalline-toamorphous structural transition, as indicated by the presence of short-range order and loss of long-range order in the RDFs. As the level of electronic concentration is relatively low and all the structural transition occurs at $300 \mathrm{~K}$, these calculations suggest that titanate pyrochlores should be readily amorphized under local ionization rates that produce these levels electronic excitation. Ion irradiation of titanate pyrochlores $\left(\mathrm{A}_{2} \mathrm{Ti}_{2} \mathrm{O}_{7}, \mathrm{~A}=\mathrm{Sm} \text { to } \mathrm{Lu} \text {, and } \mathrm{Y}\right)^{23}$ with $1-\mathrm{MeV} \mathrm{Kr}$ ions, which have a high electronic to nuclear stopping ratio, readily leads to amorphization, consistent with our calculations.

Lian et al. have reported that the irradiation response of titanate pyrochlores to ion irradiation depends on the size and electronic configuration of A-site cations, and $\mathrm{Gd}_{2} \mathrm{Ti}_{2} \mathrm{O}_{7}$ is the most easily amorphized $^{23}$. To explore the difference in radiation resistance between the three titanate pyrochlores investigated here, we have explored how the excitation concentration of each compound influences its transition temperature. For each electronic concentration, the simulations were first performed at $100 \mathrm{~K}$. If no structural transition occurs, the simulation was restarted at higher temperature with a temperature increment of $100 \mathrm{~K}$. The temperatures at which structural amorphization starts to occur are then determined as the transition temperature. The considered excitation concentration varies from $0.33 \%$ to $1.68 \%$. The change in transition temperature with excitation concentration for each compound is shown in Fig. 8. The transition temperatures are found to depend on the concentration of excited electrons for all compounds, and the temperature decreases with increasing excitation concentration. We also find that the transition temperature for $\mathrm{Y}_{2} \mathrm{Ti}_{2} \mathrm{O}_{7}$ is higher than that of $\mathrm{Gd}_{2} \mathrm{Ti}_{2} \mathrm{O}_{7}$ and $\mathrm{Sm}_{2} \mathrm{Ti}_{2} \mathrm{O}_{7}$; therefore, within the considered range of excitation concentration, $\mathrm{Y}_{2} \mathrm{Ti}_{2} \mathrm{O}_{7}$ is relatively more radiation resistant. On the other hand, the transition temperature for $\mathrm{Gd}_{2} \mathrm{Ti}_{2} \mathrm{O}_{7}$ is comparable to that for $\mathrm{Sm}_{2} \mathrm{Ti}_{2} \mathrm{O}_{7}$, indicating a similar radiation resistance to electronic excitation. This is consistent with ion irradiation experi-
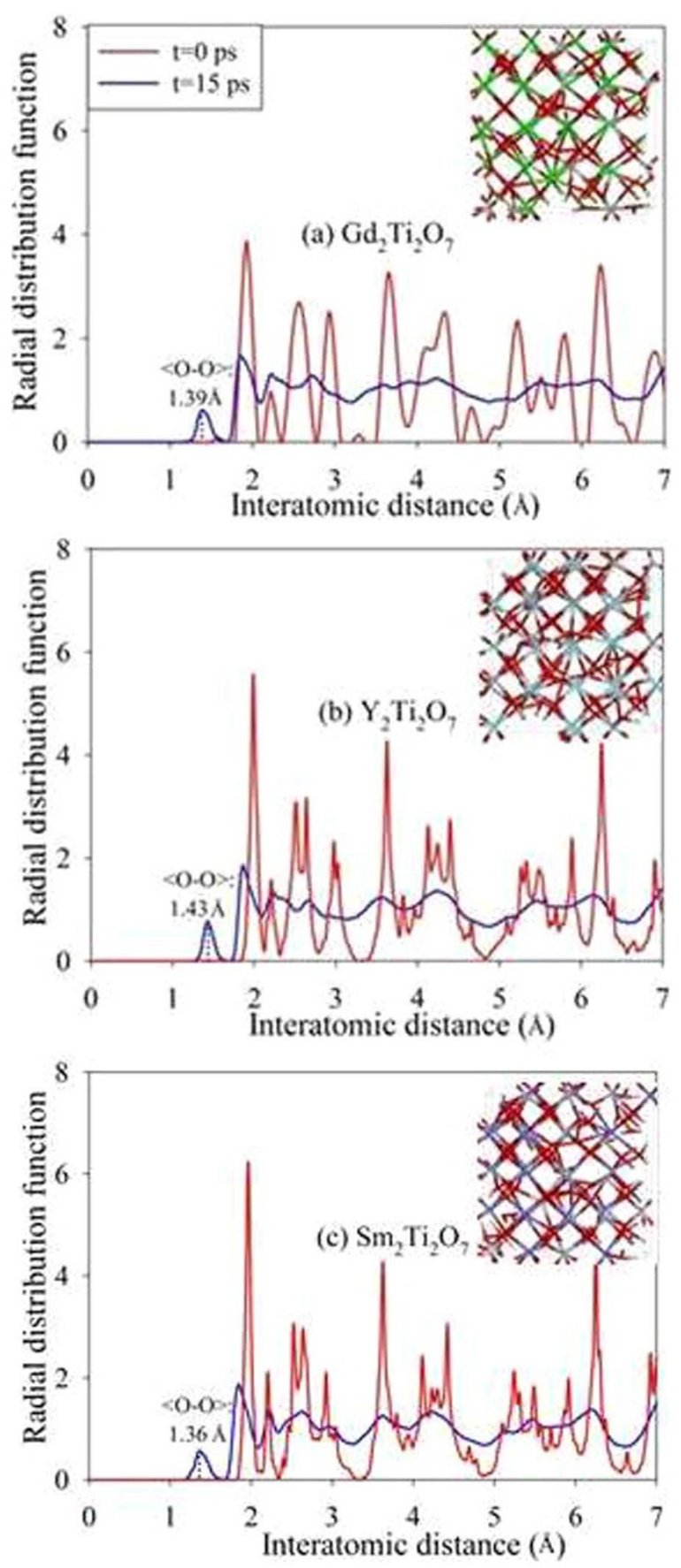

Figure 7 Comparison of radial distribution functions for titanate pyrochlores.

ments, where $\mathrm{Y}_{2} \mathrm{Ti}_{2} \mathrm{O}_{7}$ is more resistant to amorphization than $\mathrm{Gd}_{2} \mathrm{Ti}_{2} \mathrm{O}_{7}$ and $\mathrm{Sm}_{2} \mathrm{Ti}_{2} \mathrm{O}_{7}$ under $1-\mathrm{MeV} \mathrm{Kr}$ ions irradiation ${ }^{23}$. In our simulation only electronic excitation is considered, whereas in ion irradiation experiments both atomic collision and electronic excitation may contribute to the structural amorphization. When the electronic concentration is lower than $0.33 \%$, the dependence of transition temperature on excitation concentration is not clear. The calculated melting temperatures of $1875 \mathrm{~K}$ for $\mathrm{Gd}_{2} \mathrm{Ti}_{2} \mathrm{O}_{7}$, $2100 \mathrm{~K}$ for $\mathrm{Y}_{2} \mathrm{Ti}_{2} \mathrm{O}_{7}$ and $1850 \mathrm{~K}$ for $\mathrm{Sm}_{2} \mathrm{Ti}_{2} \mathrm{O}_{7}$ are also presented in Fig. 8. Our calculations indicate that increasing electronic excitation can effectively reduce the melting temperature. It should be pointed out that, at each electronic concentration, the electronic excitation is simulated for $12 \mathrm{ps}$, which is adequate to ensure the system reaches an equilibrium state. Figure 9 shows variation of 


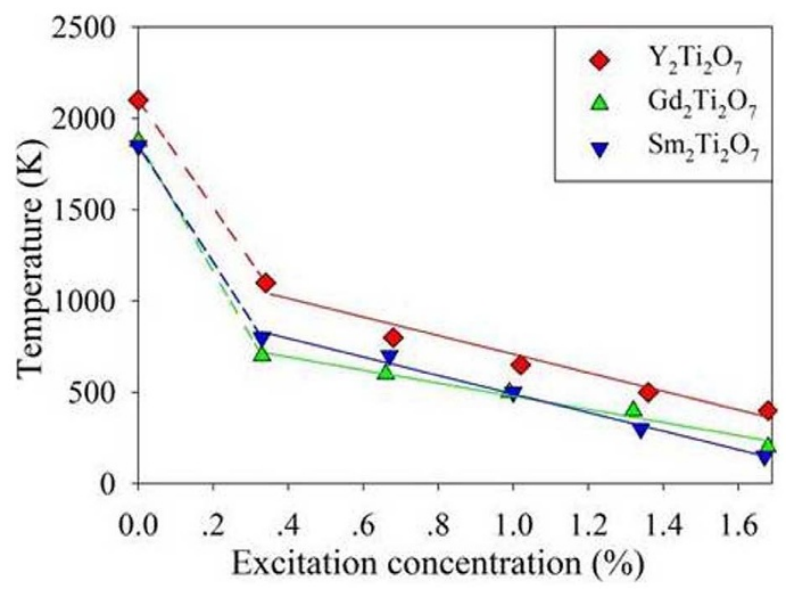

Figure 8 Transition temperatures of titanate pyrochlores as a function of excitation concentration. The calculated and fitted results are represented by symbols and solid lines, respectively.

the system energy for $\mathrm{Gd}_{2} \mathrm{Ti}_{2} \mathrm{O}_{7}$ (with $\sim 1.32 \%$ excitation) with time at transition temperature of $400 \mathrm{~K}$. The changes in system energy at $300 \mathrm{~K}$, where crystalline-to-amorphous transition does not occur, are also presented. It is obvious that the system reaches equilibrium states within 12 ps at both temperatures. The time of transition for titanate pyrochlores (with $\sim 1.64 \%$ excitation) as a function of temperature is presented in Fig. 10. It is noted that in all cases the time of transition decreases with increasing temperature. At $400 \mathrm{~K}$ the crystalline-to-amorphous transition time is predicted to be only 3.9, 3.3 and 2.7 ps for $\mathrm{Y}_{2} \mathrm{Ti}_{2} \mathrm{O}_{7}, \mathrm{Gd}_{2} \mathrm{Ti}_{2} \mathrm{O}_{7}$ and $\mathrm{Sm}_{2} \mathrm{Ti}_{2} \mathrm{O}_{7}$, respectively, indicating that the transition is very fast. Unfortunately, no experimental data are available in the literature to validate such processes.

Comparing the RDF for crystalline and amorphous states, as shown in Fig. 7, we find the most striking feature for the amorphous state is that a new $<\mathrm{O}-\mathrm{O}>$ peak forms upon structural amorphization. Fig. 11 illustrates the radial distribution function for $\langle\mathrm{O}-\mathrm{O}\rangle$ bond in $\mathrm{Gd}_{2} \mathrm{Ti}_{2} \mathrm{O}_{7}$ (with $1.64 \%$ excitation at $300 \mathrm{~K}$ ). It is shown that with time evolution more and more $\langle\mathrm{O}-\mathrm{O}\rangle$ chemical bonds are formed and the bonding distance of $1.17 \sim 1.46 \AA$ is close to that of an oxygen molecule, i.e., $1.24 \AA$, suggesting that $\mathrm{O}_{2}$-like molecules are formed during the amorphization process. Similar phenomena have been observed for $\mathrm{Y}_{2} \mathrm{Ti}_{2} \mathrm{O}_{7}$ and $\mathrm{Sm}_{2} \mathrm{Ti}_{2} \mathrm{O}_{7}$, for which the average $<\mathrm{O}-\mathrm{O}>$ bonding distances at 15 ps are 1.43 and $1.36 \AA$, respectively. In Fig. 3 , we note that, at $\mathrm{t}=0.3 \mathrm{ps}$, the $<\mathrm{O}-\mathrm{O}>$ bonds appear, which are marked by the circle, while other chemical bonds, includ-

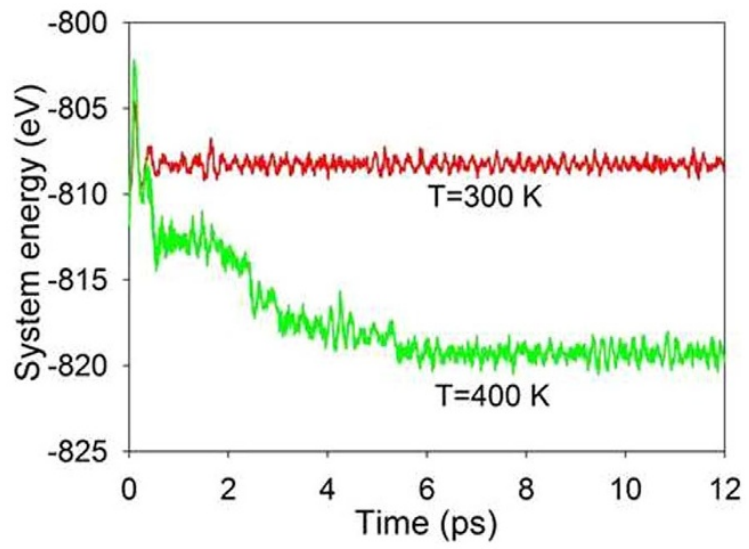

Figure 9 | Variation of system energy for $\mathrm{Gd}_{2} \mathrm{Ti}_{2} \mathrm{O}_{7}$ (with $\sim 1.32 \%$ excitation) with time evolution at 300 and $400 \mathrm{~K}$.

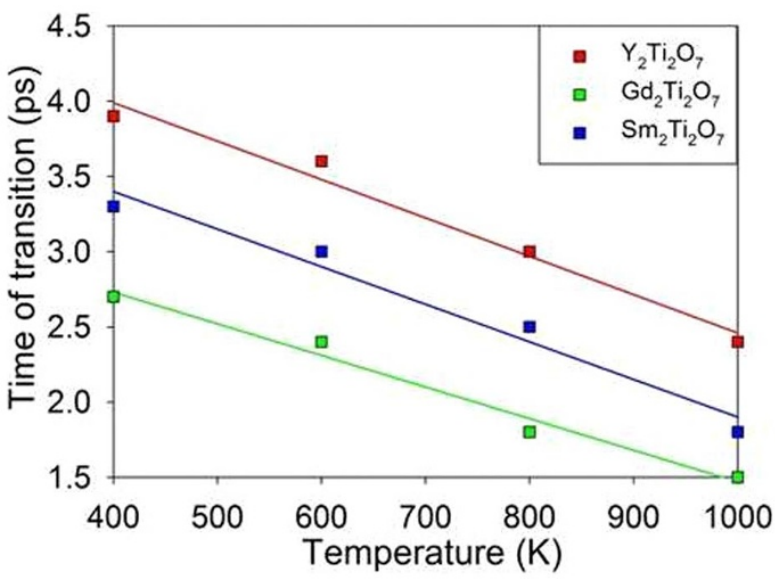

Figure 10 | Time of transition for titanate pyrochlores as a function of temperature. The calculated and fitted results are represented by symbols and solid lines, respectively.

ing $\langle\mathrm{Gd}-\mathrm{O}\rangle$, $\langle\mathrm{Ti}-\mathrm{O}\rangle$ and $\langle\mathrm{Gd}-\mathrm{Ti}\rangle$ bonds, remain nearly unchanged. With further time evolution, the disordering of other chemical bonds occurs, and complete amorphization takes place at $t=3$ ps. These results indicate that anion disorder and cation disorder do not occur concurrently under these conditions.

The MSDs for $\mathrm{A}$, Ti and $\mathrm{O}$ in $\mathrm{A}_{2} \mathrm{Ti}_{2} \mathrm{O}_{7}(\mathrm{~A}=\mathrm{Gd}, \mathrm{Y}$ and $\mathrm{Sm})$ are presented in Fig. 12. It is shown that, in all the compounds, the mean square displacements for oxygen are considerably larger than those for other chemical elements, i.e., the displacement of oxygens contributes mostly to the amorphization of pyrochlores. The total density of states for titanates without and with electronic excitation $(\sim 1.64 \%$, no structural relaxation) are shown in Fig. 13. It is noted that electronic excitation results in shifts of the Fermi energy to lower energy levels, exhibiting p-type doping character. Moreover, electrons are redistributed around the Fermi level. The results in Fig. 14 illustrate the projected density of states for titanates without and with electronic excitation $(\sim 1.64 \%$, no structural relaxation). We find that the valence band maxima are mainly contributed by $\mathrm{O}$ $2 p$ orbitals hybridized with A $4 d$ or $5 d$ states and Ti $3 d$ states, and a large number of $\mathrm{O} 2 p$ electrons occupy the Fermi level. It is indicated that the valence electrons located at $\mathrm{O} 2 p$ orbitals are more readily to be excited when the transferred energy is large enough. Figure 15 shows the spin density distribution for excited $\mathrm{Gd}_{2} \mathrm{Ti}_{2} \mathrm{O}_{7}$ without structural relaxation. It is found that the charges, which are indicated by the yellow sphere, are mainly located on oxygen atoms. These results suggest that upon electronic excitation most of $\mathrm{O} 2 p$ electrons

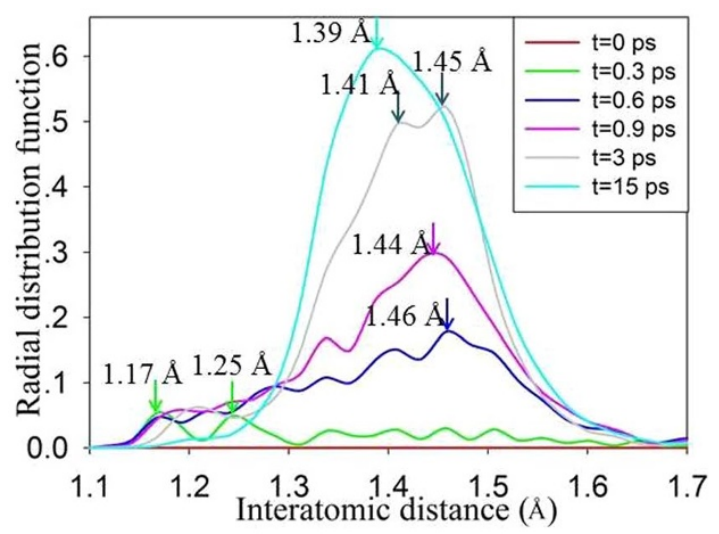

Figure $11 \mid$ Radial distribution function for $<\mathrm{O}-\mathrm{O}>$ bond in $\mathrm{Gd}_{2} \mathrm{Ti}_{2} \mathrm{O}_{7}$ (with $1.64 \%$ excitation at $300 \mathrm{~K}$ ). 

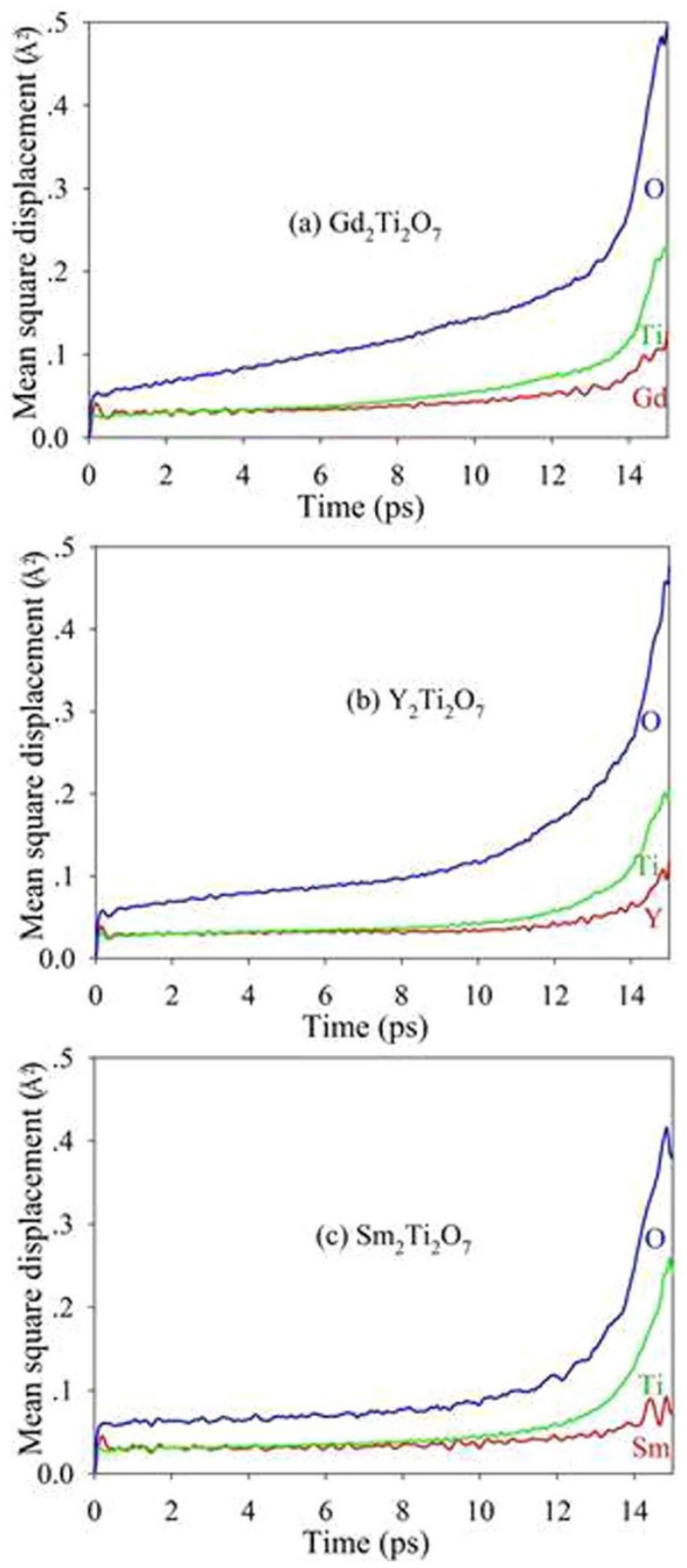

Figure 12 | Mean square displacements of titanate pyrochlores.

are excited, leading to charge redistribution and changes in interatomic potentials, which causes anion disorder and the formation of $\mathrm{O}_{2}$-like molecules. Subsequently, cation disorder is induced, and both anion and cation disorders drive the structure towards the amorphous state. Experimentally, Lian et al. also suggested that, under ion irradiation, anion disorder precedes cation disorder in $\mathrm{Gd}_{2} \mathrm{Ti}_{2} \mathrm{O}_{7}, \mathrm{Er}_{2} \mathrm{Ti}_{2} \mathrm{O}_{7}$ and $\mathrm{Lu}_{2} \mathrm{Ti}_{2} \mathrm{O}_{7}{ }^{49}$.

The amorphization mechanism revealed in this study is different from that for the intense local electronic excitation caused by swift heavy ions irradiation ${ }^{32}$. Irradiations with high energy heavy ions, such as 1.43-GeV Xe ions and 119-MeV U ions, have been carried out on $\mathrm{Gd}_{2} \mathrm{Ti}_{2} \mathrm{O}_{7}$ by Lang et al. ${ }^{29,30}$, Patel et al. ${ }^{28}$, and Sattonnay et al..$^{31,32}$ In these studies, the electronic stopping power is orders of magnitude higher than the nuclear stopping power, and the highly excited elec-
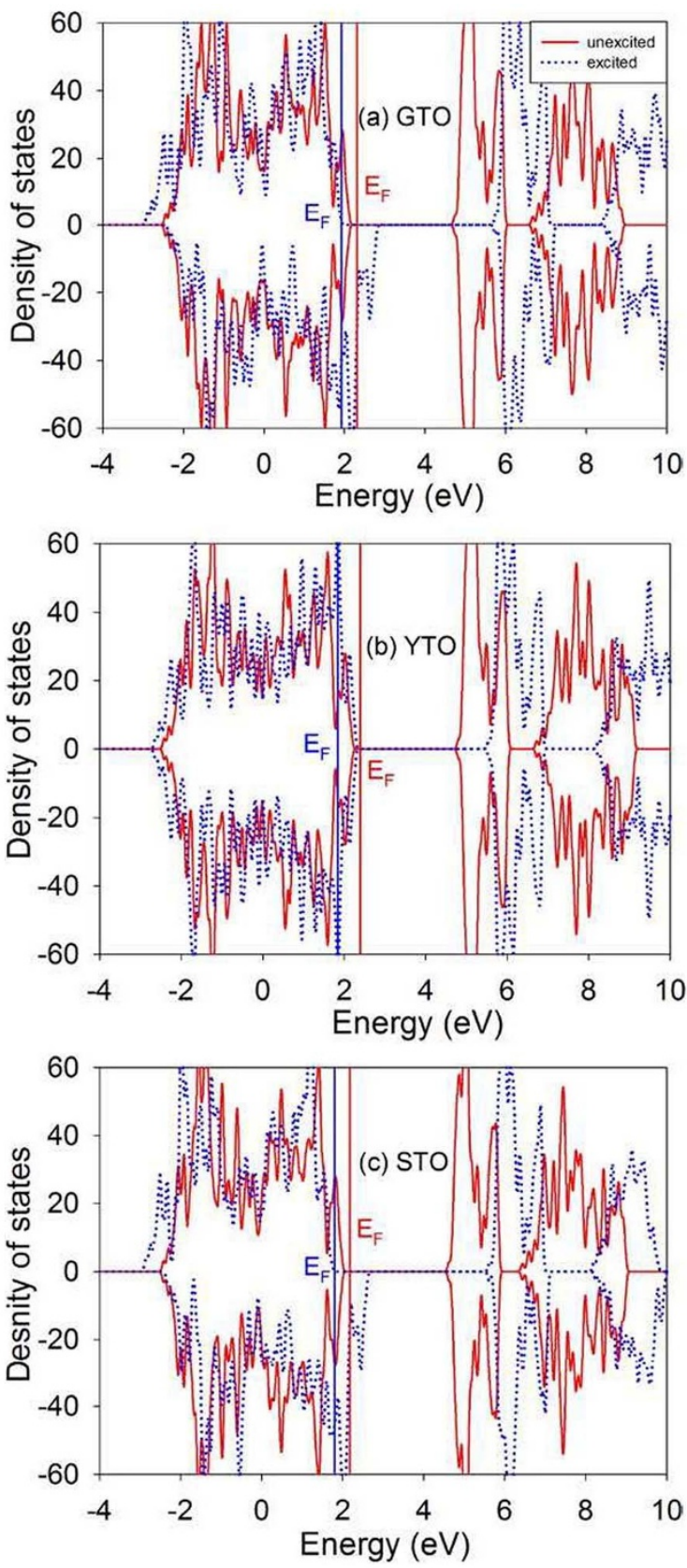

Figure $13 \mid$ Total density of states distribution for $\mathrm{Gd}_{2} \mathrm{Ti}_{2} \mathrm{O}_{7}$ (GTO), $\mathrm{Y}_{2} \mathrm{Ti}_{2} \mathrm{O}_{7}$ (YTO) and $\mathrm{Sm}_{2} \mathrm{Ti}_{2} \mathrm{O}_{7}$ (STO) without and with electronic excitation $(\sim 1.64 \%$, no structural relaxation).

trons create a local thermal spike due to electron-phonon coupling that causes local thermal melting ${ }^{50}$. The quenching of this thermal melt leads to the creation of cylindrical damaged regions, i.e., ion tracks. The formation and the overlapping of individual ion tracks ${ }^{31}$ eventually results in the crystalline-to-amorphous transition in pyrochlores $^{32}$. In our simulation, only a small concentration of electrons is excited, and there is a lack of the kinetic energy given to electrons as in the case of swift heavy ions. The results of the current study more closely simulate the irradiation with low-energy electrons, light ions, or pulsed lasers; however, it may not be easy to achieve the level of electron excitation needed to induce amorphization, without intense beams that can cause local heating. While lower levels of electronic excitation may not directly lead to amorphization at relatively low temperature, they may contribute to disordering and amorphization during atomic collision processes by destabilizing the structure, for example through broken bonds and increased energy states. The 

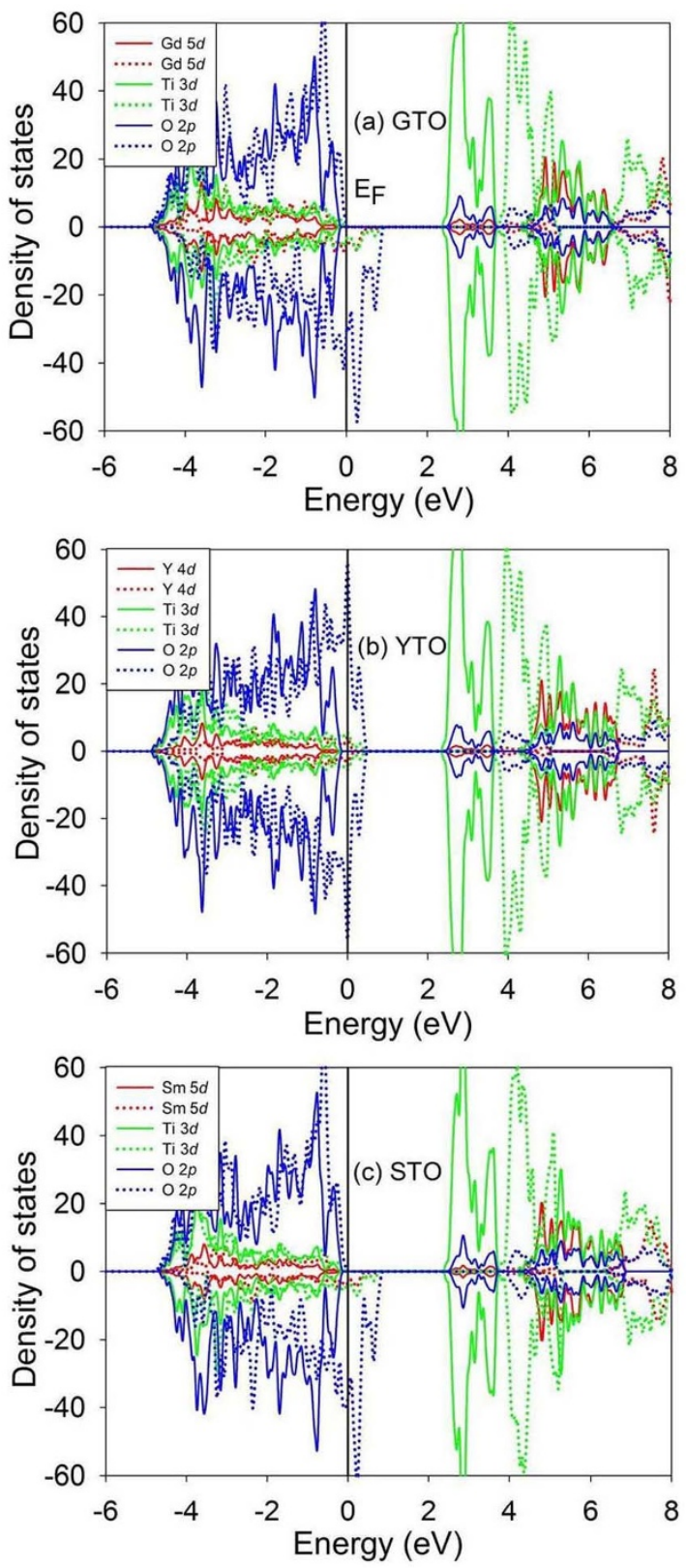

Figure $14 \mid$ Projected density of states distribution for $\mathrm{Gd}_{2} \mathrm{Ti}_{2} \mathrm{O}_{7}$ (GTO), $\mathrm{Y}_{2} \mathrm{Ti}_{2} \mathrm{O}_{7}$ (YTO) and $\mathrm{Sm}_{2} \mathrm{Ti}_{2} \mathrm{O}_{7}$ (STO) without and with electronic excitation $(\sim 1.64 \%$, no structural relaxation).

results of this study should encourage carefully designed experimental investigations to validate the predictions.

\section{Conclusions}

In summary, an ab initio $\mathrm{MD}$ method has been employed to study the structural stability of $\mathrm{Y}_{2} \mathrm{Ti}_{2} \mathrm{O}_{7}, \mathrm{Gd}_{2} \mathrm{Ti}_{2} \mathrm{O}_{7}$ and $\mathrm{Sm}_{2} \mathrm{Ti}_{2} \mathrm{O}_{7}$ under electronic excitation. It is shown that a crystalline-to-amorphous structural transition can be induced in each of the titanate pyrochlores by electronic excitation. This electronic excitation-induced amorphization is a solid-solid transition rather than a solid-liquid transition. The temperature at which structural amorphization starts to occur has been determined for each compound with excitation concentration varying from $0.3 \%$ to $2.11 \%$. For all compounds, this transition temperature depends on the concentration of excited electrons and decreases with increasing excitation concentration. The transition temperature for $\mathrm{Y}_{2} \mathrm{Ti}_{2} \mathrm{O}_{7}$ is higher than that of $\mathrm{Gd}_{2} \mathrm{Ti}_{2} \mathrm{O}_{7}$ and $\mathrm{Sm}_{2} \mathrm{Ti}_{2} \mathrm{O}_{7}$, and the transition temperatures for $\mathrm{Gd}_{2} \mathrm{Ti}_{2} \mathrm{O}_{7}$ and

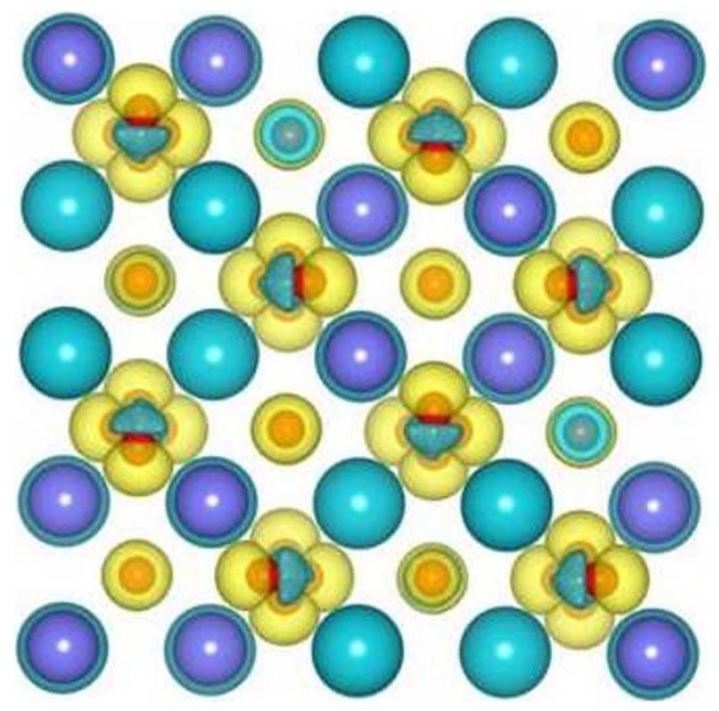

Figure $15 \mid$ Spin density distribution for $\mathrm{Gd}_{2} \mathrm{Ti}_{2} \mathrm{O}_{7}$ with $\sim 1.64 \%$ excitation (without relaxation).

$\mathrm{Sm}_{2} \mathrm{Ti}_{2} \mathrm{O}_{7}$ are comparable to each other. When electronic excitation occurs, the excitation of $\mathrm{O} 2 p$ electrons dominates, which causes anion disorder and the formation of $\mathrm{O}_{2}$-like molecules. Cation disorder is further induced by anion disorder, and both drive the structure towards the amorphous state. The mechanism for amorphization induced by electronic excitation in this study is different from that caused by the intense local electronic excitation from swift heavy ions, which occurs by thermal melting. This study indicates the importance of electronic excitation in phase transition processes in pyrochlores under electron, ion and pulsed laser irradiations, and it provides insights on the use of intense ionizing irradiation for micromachining, surface modifications, and thin film processing.

1. Xiao, H. Y., Gao, F. \& Weber, W. J. Threshold displacement energies and defect formation energies in $\mathrm{Y}_{2} \mathrm{Ti}_{2} \mathrm{O}_{7}$. J. Phys.: Condens. Matter 22, 415801 (2010).

2. Jiang, C., Stanek, C. R., Sickafus, K. E. \& Uberuaga, B. P. First-principles prediction of disordering tendencies in pyrochlore oxides. Phys. Rev. B 79, 104203 (2009).

3. Ewing, R. C., Weber, W. J. \& Lian, J. Nuclear waste disposal-pyrochlore $\left(\mathrm{A}_{2} \mathrm{~B}_{2} \mathrm{O}_{7}\right)$ : Nuclear waste form for the immobilization of plutonium and "minor" actinides. J. Appl. Phys. 95, 5949 (2004).

4. Moon, P. K., Tuller, H. L. \& Actuat, S. Evaluation of the $\mathrm{Gd}_{2}\left(\mathrm{Zr}_{\mathrm{x}} \mathrm{Ti}_{1-\mathrm{x}}\right)_{2} \mathrm{O}_{7}$ pyrochlore system as an oxygen gas sensor. Sens. Actuators. B 1, 199 (1990).

5. Zhang, Z. L., Xiao, H. Y., Zu, X. T., Gao, F. \& Weber, W. J. First-principles calculation of structural and energetic properties for $\mathrm{A}_{2} \mathrm{Ti}_{2} \mathrm{O}_{7}(\mathrm{~A}=\mathrm{Lu}, \mathrm{Er}, \mathrm{Y}, \mathrm{Gd}$, Sm, Nd, La). J. Mater. Res. 24, 1335 (2009).

6. Xiao, H. Y., Zu, X. T., Gao, F. \& Weber, W. J. First-principles study of energetic and electronic properties of $\mathrm{A}_{2} \mathrm{Ti}_{2} \mathrm{O}_{7}(\mathrm{~A}=\mathrm{Sm}, \mathrm{Gd}, \mathrm{Er})$ pyrochlore. J. Appl. Phys. 104, 073503 (2008).

7. Weber, W. J. \& Ewing, R. C. Plutonium immobilization and radiation effects. Science 289, 2051 (2000).

8. Weber, W. J., Wald, J. W. \& Matzke, H. Self-radiation damage in $\mathrm{Gd}_{2} \mathrm{Ti}_{2} \mathrm{O}_{7}$. Mater. Lett. 3, 173 (1985).

9. Xiao, H. Y., Gao, F. \& Weber, W. J. Ab initio investigation of phase stability of $\mathrm{Y}_{2} \mathrm{Ti}_{2} \mathrm{O}_{7}$ and $\mathrm{Y}_{2} \mathrm{Zr}_{2} \mathrm{O}_{7}$ under high pressure. Phys. Rev. B 80, 212102 (2009).

10. Weber, W. J. et al. Radiation effects in crystalline ceramics for the immobilization of high-level nuclear waste and plutonium. J. Mater. Res. 13, 1434 (1998).

11. Sickafus, K. E. et al. Radiation tolerance of complex oxides. Science 289, 748 (2000).

12. Chartier, A., Catillon, G. \& Crocombette, J. P. Key Role of the Cation Interstitial Structure in the Radiation Resistance of Pyrochlores. Phys. Rev. Lett. 102, 155503 (2009).

13. Chartier, A., Meis, C., Crocombette, J. P., Weber, W. J. \& Corrales, L. R. Molecular dynamic simulation of disorder induced amorphization in pyrochlore. Phys. Rev. Lett. 94, 025505 (2005).

14. Sickafus, K. E. et al. Radiation-induced amorphization resistance and radiation tolerance in structurally related oxides Nat. Mater. 6, 217 (2007).

15. Devanathan, R., Weber, W. J. \& Gale, J. D. Radiation tolerance of ceramicsinsights from atomistic simulation of damage accumulation in pyrochlores Energy Environ. Sci. 3, 1551 (2010). 
16. Li, Y. H. et al. Role of Antisite Disorder on Preamorphization Swelling in Titanate Pyrochlores. Phys. Rev. Lett. 108, 195504 (2012).

17. Cheng, J. G., Wang, J. L., Dechakupt, T. \& Trolier-McKinstry, S. Low-temperature crystallized pyrochlore bismuth zinc niobate thin films by excimer laser annealing. Appl. Phys. Lett. 87, 232905 (2005).

18. Shamoto, S. et al. Light-induced metal-insulator transition in Lu2V2O7. J. Phys. Chem. Solids 62, 325 (2001).

19. Pillonnet, A. et al. Thin film growth using hetero embryo: demonstration on pyrochlore phase. ACS Appl. Mater. Interfaces 2, 1543 (2010).

20. Weber, W. J., Wald, J. W. \& Matzke, H. Effects of self-radiation damage in $\mathrm{Cm}$ doped $\mathrm{Gd}_{2} \mathrm{Ti}_{2} \mathrm{O}_{7}$ and $\mathrm{CaZrTi}_{2} \mathrm{O}_{7}$. J. Nucl. Mater. 138, 196 (1986).

21. Wang, S. X. et al. Radiation stability of gadolinium zirconate: a waste form for plutonium disposition. J. Mater. Res. 14, 4470 (1999).

22. Weber, W. J. \& Wald, J. W. Self-radiation damage in $\mathrm{Gd}_{2} \mathrm{Ti}_{2} \mathrm{O}_{7}$. Mater. Lett. 3, 173 (1985).

23. Lian, J., Chen, J., Wang, L. M. \& Ewing, R. C. Radiation-induced amorphization of rare-earth titanate pyrochlores. Phys. Rev. B 68, 134107 (2003).

24. Weber, W. J. Models and mechanisms of irradiation-induced amorphization in ceramics. Nucl. Instrum. Methods Phys. Res., Sect. B 166-167, 98-106 (2000).

25. Zhang, Y. et al. Damage evolution on Sm and O sublattices in Au-implanted samarium titanate pyrochlore. J. Appl. Phys. 95, 2866 (2004).

26. Mafi, E., Soudi, A. \& Gu, Y. Electronically driven amorphization in phase-change $\mathrm{In}_{2} \mathrm{Se}_{3}$ nanowires. J. Phys. Chem. C 116, 22539 (2012).

27. Kolobov, A. V., Krbal, M., Fons, P., Tominaga, J. \& Uruga, T. Distortion-triggered loss of long-range order in solids with bonding energy hierarchy. Nature Chem. 3, 311 (2011)

28. Patel, M. K. et al. Structural modifications in pyrochlores caused by ions in the electronic stopping regime. J. Nucl. Mater. 380, 93 (2008).

29. Lang, M. et al. Single-ion tracks in $\mathrm{Gd}_{2} \mathrm{Zr}_{2(1-x)} \mathrm{Ti}_{\mathrm{x}} \mathrm{O}_{7}$ pyrochlores irradiated with swift heavy ions. Phys. Rev. B 79, 224105 (2009).

30. Zhang, J. et al. Nanoscale phase transitions under extreme conditions within an ion track. J. Mater. Res. 25, 1344 (2010).

31. Sattonnay, G. et al. Phase transformations induced by high electronic excitation in ion-irradiated $\mathrm{Gd}_{2}\left(\mathrm{Zr}_{\mathrm{x}} \mathrm{Ti}_{1-\mathrm{x}}\right)_{2} \mathrm{O}_{7}$ pyrochlores. J. Appl. Phys. 108, 103512 (2010).

32. Sattonnay, G. et al. Effect of composition on the behavior of pyrochlores irradiated with swift heavy ions. Nucl. Instrum. Methods B 272, 261-265 (2012).

33. Devanathan, R., Gao, F. \& Sundgren, C. J. Role of cation choice in the radiation tolerance of pyrochlores. Rsc. Adv. 3, 2901 (2013).

34. Wang, J. W., Lang, M., Ewing, R. C. \& Becker, U. Multi-scale simulation of structural heterogeneity of swift-heavy ion tracks in complex oxides. J. Phys. Condens. Matter 25, 135001 (2013).

35. Moll, S. et al. Irradiation damage in $\mathrm{Gd}_{2} \mathrm{Ti}_{2} \mathrm{O}_{7}$ single crystals: Ballistic versus ionization processes. Phys. Rev. B 84, 064115 (2011).

36. Thomé, L. et al. Combined effects of nuclear and electronic energy losses in solids irradiated with a dual-ion beam. Appl. Phys. Lett. 102, 141906 (2013).

37. Weber, W. J. \& Roberts, F. P. A review of radiation effects in solid nuclear waste forms. Nucl. Technol. 60, 178 (1983).

38. Weber, W. J. et al. Radiation effects in glasses used for immobilization of highlevel waste and plutonium disposition. J. Mater. Res. 12, 1946 (1997).

39. Zhang, Y. et al. Ion-induced damage accumulation and electron-beam-enhanced recrystallization in $\mathrm{SrTiO}_{3}$. Phys. Rev. B 72, 094112 (2005).

40. Bae, I.-T., Zhang, Y., Weber, W. J., Higuchi, M. \& Giannuzzi, L. A. Electron-beam induced recrystallization in amorphous apatite. Appl. Phys. Lett. 90, 021912 (2007).

41. Zhang, Y., Bae, I.-T. \& Weber, W. J. Atomic collision and ionization effects in oxides. Nucl. Instrum. Methods B 266, 2828-2833 (2008).
42. Wang, X. J., Xiao, H. Y., Zu, X. T., Zhang, Y. \& Weber, W. J. Ab initio molecular dynamics simulations of ion-solid interactions in $\mathrm{Gd}_{2} \mathrm{Zr}_{2} \mathrm{O}_{7}$ and $\mathrm{Gd}_{2} \mathrm{Ti}_{2} \mathrm{O}_{7}$. J. Mater. Chem. C 1, 1665 (2013).

43. Gao, F., Xiao, H. Y., Zu, X. T., Posselt, M. \& Weber, W. J. Defect-Enhanced Charge Transfer by Ion-Solid Interactions in SiC using Large-Scale Ab Initio Molecular Dynamics Simulations. Phys. Rev. Lett. 103, 027405 (2009).

44. G, K. \& J, F. Efficient iterative schemes for ab initio total-energy calculations using a plane-wave basis set. Phys. Rev. B 54, 11169 (1996).

45. Blöchl, P. E. Projector augmented-wave method. Phys. Rev. B 50, 17953 (1994).

46. Monkhorst, H. J. \& Pack, J. D. Special points for Brillouin-zone integrations. Phys. Rev. B 13, 5188 (1976).

47. Li, X. et al. Role of electronic excitation in the amorphization of Ge-Sb-Te alloys. Phys. Rev. Lett. 107, 015501 (2011).

48. Shcherbakova, L. G., Mamsurova, L. G. \& Sukhanova, G. E. Rare earth titanates. (Chernogolovka, 1978).

49. Lian, J. et al. The order-disorder transition in ion-irradiated pyrochlore. Acta. Mater. 51, 1493 (2003)

50. Zhang, J. et al. Nanoscale phase transitions under extreme conditions within an ion track. J. Mater. Res. 25, 1334 (2010).

\section{Acknowledgments}

H.Y. Xiao was supported by the scientific research starting funding of University of Electronic Science and Technology of China (Grant No. Y02002010401085) and by the NSAF Joint Foundation of China (Grant No. U1330103). W.J. Weber and Y. Zhang were supported by the U.S. Department of Energy, Office of Science, Basic Energy Science, Materials Sciences and Engineering Division. The theoretical calculations were performed using the supercomputer resources at TianHe-1 located at National Supercomputer Center in Tianjin and the resources of the National Energy Research Scientific Computing Center, supported by the Office of Science, US Department of Energy under Contract No. DEAC02-05CH11231.

\section{Author contributions}

W.W., Y.Z. and X.Z. designed the calculations. H.X. conducted the calculations and wrote the manuscript. S. Li contributed to the discussion and interpretation of the results. All authors discussed the results and reviewed the manuscript.

\section{Additional information}

Supplementary information accompanies this paper at http://www.nature.com/ scientificreports

Competing financial interests: The authors declare no competing financial interests. How to cite this article: Xiao, H.Y., Weber, W.J., Zhang, Y., Zu, X.T. \& Li, S. Electronic excitation induced amorphization in titanate pyrochlores: an ab initio molecular dynamics study. Sci. Rep. 5, 8265; DOI:10.1038/srep08265 (2015).

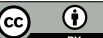

This work is licensed under a Creative Commons Attribution 4.0 Internation License. The images or other third party material in this article are included in the article's Creative Commons license, unless indicated otherwise in the credit line; if the material is not included under the Creative Commons license, users will need to obtain permission from the license holder in order to reproduce the material. To view a copy of this license, visit http://creativecommons.org/licenses/by/4.0/ 